which the Government has allowed itself to be unduly influenced by the comparative cheapness of building at Stansted. The signs are that it will cost $£ 47$ million to provide the airport with a second runway and the terminal buildings to go with it, as well as to provide a link with the railway nearby. With a close approximation to glee, the White Paper seizes on the fact that the marshy sites in the Thames estuary would be much more expensive to develop. Indeed, the best of them, at Sheppey, would require something like $£ 15$ million extra because of the terrain, while the White Paper makes much of the fact that building at Sheppey would put a military firing range out of action, at a notional cost of $£ 25$ million, and that it would be necessary to provide an entirely new rail link at a cost of $£ 40$ million. This is largely special pleading. For one thing, there may well be good economic reasons why the third London airport would be more valuableand more widely used by passengers and airlines alikeif it were provided with a brand-new rail link even at a cost of $£ 40$ million than Stansted will be with its makeshift arrangements for getting passengers to their aircraft. Indeed, the most depressing feature of this new decision is that the design of the third airport seems destined to be entirely unmodern. Nobody seems seriously to have considered whether passengers will be prepared, in the mid-seventies, to spend as much time getting to the airport as crossing the Atlantic, and nobody seems to have asked how much they would be prepared to pay for a reasonably quick means of access.

These, however, are only obvious defects in the thinking behind the third airport. It seems passively to be accepted that airport operations in the future will continue to involve the collection of huge and increasing numbers of people into city airline terminals and their mass transport from there to some distant airstrip. On the face of things, at least, there would be great advantages in linking the city transport network as a whole to airline transit, possibly by making each railway and subway station into a putative check-in point. And what of the potential usefulness of helicopters? Is it to be assumed that they will never have a useful contribution to make? And what of the possibility that much more economical use of air space above crowded cities might be made by investing really large sums of money in air traffic control techniques? As things are, the rules of thumb developed since the war are now in the process of being sanctified and made permanent. The sad truth unfortunately is that in this and many other ways the Government seems bent on having an unfashionable airport for the seventies - a thoughtless monument to the times when air travel was still a kind of nine days wonder.

\section{WHAT IS SCRAPIE?}

THE disease called scrapie, which affects sheep and goats, is clearly more than an unsolved puzzle. The article by Dr. T. Alper and her colleagues on page 764 adds further to the suggestions there have been in recent months that the infective agent, usually thought to be a virus, is not entirely straightforward. For some time, of course, it has been known that the scrapie agent, whatever its nature, is unusually insensitive to heat and other indignities. On some assumptions, gamma irradiation has suggested that the potentially destructible part of the agent may be very small-just $7 \mathrm{~m} \mu$ or so-and there have recently been suggestions (Pattison, I. H., and Jones, K. M., Vet. Rec., 80, 2; 1967) that it is nothing but a specific protein molecule. What has now been done is to show that the scrapie agent seems to be unusually resistant to ultra-violet light, even at a wavelength known to be damaging to most viruses, and even when the wavelength is chosen to be one to which proteins are known to be sensitive. Whether it can safely be inferred from all this that the infective agent is really a carbohydrate molecule-one of the possibilities which has been suggested-is, of course, another matter, and will not be settled finally until the infective agent has been isolated fully characterized. The difficulties of experimental work with scrapie are relevant in this connexion. For one thing, the virus cannot yet be grown in tissue culture. Assay depends on the infection of mice and the recognition of lesions in the brain after an interval of several months-a technique the only virtue of which is that it is better than anything else. Recovering the agent in pure form from preparations like these is technically extremely difficult. In the circumstances, of course, it will be no surprise if the controversy about the detailed interpretation of experiments with scrapie continues for some time.

It would, however, be unreasonable to expect that speculation will wait on the conclusion of experiments not yet begun. The recent flurry of excitement about the character of scrapie has already stimulated interest in other infections of the nervous system-kuru, for example. The suggestion that the infecting agent of scrapie may be a self-replicating entity without nucleic acid is also not without virtue, if only as a challenge. In this connexion, it is worth recalling that even if the infective agent lacked nucleic acid, it is conceivable that the processes of infection and of replication might be fitted into the now accepted framework of how protein synthesis in cells is regulated. One theoretical possibility (with no evidence to support it) is that molecules of the agent might have the function of inducing metabolic processes the products of which include molecules of the inducer itself. It may be relevant that in some bacteria, at least, protein molecules responsible for switching off certain genetic functions have now been identified. Carbohydrate molecules would be harder to accommodate than protein molecules, not least of all because the chemistry of carbohydrates is so shot through with uncertainty. Saving the appearances is not, however, the object of the exercise. 